\title{
The Impact of Demographic Characteristics on Art Appreciation: Take Recitation Activities as an Example
}

\author{
Siming Wang \\ Art College, Xiamen University, Xiamen 361000, China \\ 824230265@qq.com
}

Keywords: Demographic characteristics, art appreciation, recitation activities.

\begin{abstract}
Since 2008 when the first City Recitation Festival was held in Huli District, Xiamen Island's recitation activities entered a stage of rapid development in general. The literature focusing on the impact of demographic characteristics on art appreciation is scarce, this study intends to bridge the gap, we use the method of questionnaire survey and empirical analysis to examine the impact of demographic characteristics on the conditions of watching recitation show, expecting to understand the development condition of recitation activities in Xiamen and making predictions on the future development direction. By analysing the existing documents and by conducting further statistical analyses, this study comes up with the conclusions that there is still space for the further development of Xiamen Island's recitation activities, that some groups interested in recitation are still waiting to be stimulated, that the recitation training market needs to be further regulated and that it's still not suggested to hold large recitation commercial performances or other similar activities.
\end{abstract}

\section{Introduction}

Recitation programs are essential language programs in large-scale theoretical performances. The purpose of the recitation programs is to evoke an atmosphere in the theoretical performance and to cater to the psychic core of the performance. In other words, these recitation programs are particularly created to meet the needs of propaganda. From the perspective of art, the recitation art can be regarded as an extension of the art of writing (such as prose, poetry), as well as an important constituent of the language art. From the individual perspective, the art of recitation is a combination of one's personal reciting habits and one's interpretation of the manuscripts. Recitation hasn't received as much attention as other arts (such as painting, designing, music etc.). However, due to recitation's features of being close to life and a lower threshold for the beginners, it's more likely for the art of recitation to get popular among the grass-roots units.

The existing documents mainly elaborate recitation theories art in three aspects. First is about the reciter's own interpretation of the work. As recitation is a creative form of language expression, the reciter's interpretation of the work which comes from his or her long-term reading accumulation and life experience will play a major role in affecting the recitation quality. Second is how the reciter creates a certain atmosphere while reciting. The significance of creating performance atmosphere is to indirectly guide the audience to interpret the work from the reciter's point of view. To achieve this goal, there are two approaches. One is the subjective approach, which means that the reciter could use his or her experience and skills to control the voice output, including sound, intonation and tone, so as to get the audience obtain subjective artistic conception of the work; the other is the objective approach, which means to create visual and acoustic shock by employing some external means, such as background music, stage artistic design and so on, so as to construct a certain atmosphere. Third is the reciter's second creation during the show. The so-called second creation means that the reciter employs the above two approaches and his/her rich reciting techniques to make audiences not only understand the meaning of the text itself, but also get more profound and richer meaning from the work, like its time significance, historical meaning, as well 
as how the work reflects the contemporary society, and so on. Bullot and Reber (2013) proposed a psycho-historical framework for the science of art appreciation, which demonstrates that a science of art appreciation must investigate how appreciators process causal and historical information to classify and explain their psychological responses to art [1]. Jakesch and Leder (2009) tested whether the amount of information, the amount of matching information, or the proportion of matching to nonmatching statements apparent in a picture (levels of ambiguity) affect liking and interestingness [2]. Rump and Southgate stuied the pictorial interests and preferences of 7, 11 and 15-year-old children and of adults [3].

However, the literature focusing on the impact of demographic characteristics on art appreciation is scarce, this study intends to bridge the gap, this study intend to bridge the gap, we use the method of questionnaire survey and empirical analysis to examine the impact of demographic characteristics on the conditions of watching recitation show, expecting to understand the development condition of recitation activities in Xiamen and making predictions on the future development direction. Since Xiamen has implemented reform and opening up for a comparatively long time, it has deeper cultural collisions and integration compared with other inland cities. Also, the island of Xiamen contains Gulangyu Islet, which has streets of deep historic cultural heritage, and Xiamen University, which is a history-honoured, prestigious university in China. Such a strong cultural atmosphere is beneficial to the development of reading habit throughout the entire Xiamen society, and will promote the advancement of its recitation activities. This survey was conducted from 2015 to June 2016 in the two districts of Xiamen Island: Huli and Siming Districts. The selection of the survey time and sites falls into considerations in two aspects. First, timeliness is very important, and the survey is mainly focused on the development status of the recitation shows; second, there was some new recitation-related hallmark event in Xiamen during the period when the survey was conducted. Based on the empirical results, the paper has also forecast the odds for Xiamen to develop large recitation commercial performances in the future.

\section{Questionnaire Survey and Data Analyses}

To gain a better understanding of the development status and to predict the future trend of Xiamen's recitation activities, the investigator has conducted a questionnaire survey in addition to the on-the-spot investigations. The sample capacity of this survey is two hundred, and there are two hundred and twenty-four questionnaires taken back, among which only one questionnaire is invalid. The survey was conducted on the internet and 99.55\% respondents finished their questionnaires on cell phones. Through call-back research, it's found that the one invalid questionnaire comes from the first respondent, who is not a college student. It's because he has omitted the last question of the questionnaire. Therefore, all the two hundred and twenty-four questionnaires are valid with regard to the first ten questions.

The main aim of designing these questions is to cover the sample possibilities as far as possible. From the questionnaires taken back, it could be seen that this questionnaire survey has covered people of different educational degrees and income levels, so the above design aim has been generally fulfilled. After an initial analysis of the data, it could be found that the actual situation reflected in the questionnaires is basically in consistence with the survey of Xiamen Recitation Society. More females attended the questionnaire survey than males; over half respondents have a monthly income below 5999 yuan, and respondents with college or bachelor's degrees' account for $67 \%$ of all respondents; around 54\% respondents have watched live recitation performances; up to $60 \%$ respondents have chosen to watch single recitation programs in large theoretical performances. $55 \%$ respondents of the valid questionnaires have shown interest in the recitation shows, and $70 \%$ respondents will watch large independent recitation performances in the future; nearly half of the respondents are interested in the creative products related to recitation performances, but 52\% respondents will not buy tickets to watch commercial performances mainly of recitation programs [4]. 
The results of the following cross-over analyses have shown some more specific problems, and the first group of the cross-over analyses mainly manifests the relationship between the respondent's gender / educational degree and the recitation performances.

Table 1 The relationship between the respondent's gender / educational degree and the number of recitation performances he/she has watched

\begin{tabular}{|c|c|c|c|c|c|}
\hline$X \backslash Y$ & $\begin{array}{c}\text { A. Above } \\
\text { five }\end{array}$ & $\begin{array}{c}\text { B. Three } \\
\text { to five }\end{array}$ & $\begin{array}{c}\text { C. One to } \\
\text { two }\end{array}$ & D. None & Subtotal \\
\hline A. Male $\backslash$ A. Master and above & $6(26.09 \%)$ & $2(8.7 \%)$ & $5(21.74 \%)$ & $10(43.48 \%)$ & 23 \\
\hline A. Male $\backslash$ B. Bachelor & $9(28.13 \%)$ & $5(15.63 \%)$ & $7(21.88 \%)$ & $11(34.38 \%)$ & 32 \\
\hline A. Male $\backslash$ C. College & $2(13.33 \%)$ & $6(40 \%)$ & $3(20 \%)$ & $4(26.67 \%)$ & 15 \\
\hline A. Male $\backslash$ D. Below college & $0(0 \%)$ & $0(0 \%)$ & $7(63.64 \%)$ & $4(36.36 \%)$ & 11 \\
\hline B. Female $\backslash$ A. Master and above & $1(3.7 \%)$ & $2(7.41 \%)$ & $12(44.44 \%)$ & $12(44.44 \%)$ & 27 \\
\hline B. Female $\backslash$ B. Bachelor & $10(14.93 \%)$ & $14(20.9 \%)$ & $22(32.84 \%)$ & $21(31.34 \%)$ & 67 \\
\hline B. Female $\backslash$ C. College & $7(18.42 \%)$ & $8(21.05 \%)$ & $11(28.95 \%)$ & $12(31.58 \%)$ & 38 \\
\hline B. Female $\backslash$ D. Below college & $1(9.09 \%)$ & $3(27.27 \%)$ & $2(18.18 \%)$ & $5(45.45 \%)$ & 11 \\
\hline
\end{tabular}

Table 1 mainly shows the relationship between the respondent's gender / educational degree and the number of recitation performances he/she has watched. It could be seen from the percentages and numbers in the table that males of bachelor's degrees or college degrees watched more recitation performances that males of higher or lower degrees. Males of college degrees and above watched more recitation performances. The above situation is the same with the female respondents. However, female respondents clearly watched more performances than their male counterparts, which is most obvious in the case of female audiences with college degrees and below.

Table 2 The relationship between the respondent's gender / educational degree and his/her interest in recitation

\begin{tabular}{|c|c|c|c|c|}
\hline $\mathrm{X} \backslash \mathrm{Y}$ & A. Interested & B. Just so-so & C. Not interested & Subtotal \\
\hline A. Male /A. Master and above & $10(43.48 \%)$ & $10(43.48 \%)$ & $3(13.04 \%)$ & 23 \\
\hline A. Male /B. Bachelor & $19(59.38 \%)$ & $8(25 \%)$ & $5(15.63 \%)$ & 32 \\
\hline A. Male /C. College & $9(60 \%)$ & $4(26.67 \%)$ & $2(13.33 \%)$ & 15 \\
\hline A. Male /D. Below college & $5(45.45 \%)$ & $5(45.45 \%)$ & $1(9.09 \%)$ & 11 \\
\hline B. Female /A. Master and above & $8(29.63 \%)$ & $17(62.96 \%)$ & $2(7.41 \%)$ & 27 \\
\hline B. Female /B. Bachelor & $42(62.69 \%)$ & $17(25.37 \%)$ & $8(11.94 \%)$ & 67 \\
\hline B. Female /C. College & $26(68.42 \%)$ & $9(23.68 \%)$ & $3(7.89 \%)$ & 38 \\
\hline B. Female /D. Below college & $5(45.45 \%)$ & $2(18.18 \%)$ & $4(36.36 \%)$ & 11 \\
\hline
\end{tabular}

Similar to Table 1, Table 2 shows that males of bachelor's degrees or college degrees are more interested in recitation performances. Among them, those who chose "interested" account for $60 \%$ or nearly $60 \%$ of all the questionnaire respondents. Similarly, over $60 \%$ females of bachelor's degrees or college degrees are interested in recitation. Whereas, different from their male counterparts, females with educational degrees below college are far more interested in recitation than females of master degrees and above. 
Table 3 The relationship between the respondent's gender / educational degree and whether he/she will watch the independent recitation performances [5]

\begin{tabular}{|c|c|c|c|}
\hline $\mathrm{X} \backslash \mathrm{Y}$ & A. Yes & B. No & Subtotal \\
\hline A. Male /A. Master and above & $16(69.57 \%)$ & $7(30.43 \%)$ & 23 \\
\hline A. Male /B. Bachelor & $22(68.75 \%)$ & $10(31.25 \%)$ & 32 \\
\hline A. Male /C. College & $12(80 \%)$ & $3(20 \%)$ & 15 \\
\hline A. Male /D. Below college & $7(63.64 \%)$ & $4(36.36 \%)$ & 11 \\
\hline B. Female /A. Master and above & $17(62.96 \%)$ & $10(37.04 \%)$ & 27 \\
\hline B. Female /B. Bachelor & $47(70.15 \%)$ & $20(29.85 \%)$ & 67 \\
\hline B. Female /C. College & $30(78.95 \%)$ & $8(21.05 \%)$ & 38 \\
\hline B. Female /D. Below college & $6(54.55 \%)$ & $5(45.45 \%)$ & 11 \\
\hline
\end{tabular}

The feature of Table 3 is that over a half respondent

will watch independent recitation performances. It could be seen through analyses that over $60 \%$ male respondents will watch independent recitation performances, except those of college degrees. As for female respondents, those who will watch independent recitation performances are mainly females of bachelor's degrees or college degrees.

Table 4 The relationship between the respondent's gender / educational degree and whether he/she will buy ticket to watch recitation commercial performances

\begin{tabular}{|c|c|c|c|}
\hline $\mathrm{X} \backslash \mathrm{Y}$ & A. Yes & B. No & Subtotal \\
\hline A. Male /A. Master and above & $11(47.83 \%)$ & $12(52.17 \%)$ & 23 \\
\hline A. Male /B. Bachelor & $16(50 \%)$ & $16(50 \%)$ & 32 \\
\hline A. Male /C. College & $11(73.33 \%)$ & $4(26.67 \%)$ & 15 \\
\hline A. Male /D. Below college & $6(54.55 \%)$ & $5(45.45 \%)$ & 11 \\
\hline B. Female /A. Master and above & $8(29.63 \%)$ & $19(70.37 \%)$ & 27 \\
\hline B. Female /B. Bachelor & $28(41.79 \%)$ & $39(58.21 \%)$ & 67 \\
\hline B. Female /C. College & $22(57.89 \%)$ & $16(42.11 \%)$ & 38 \\
\hline B. Female /D. Below college & $5(45.45 \%)$ & $6(54.55 \%)$ & 11 \\
\hline
\end{tabular}

From the overall percentages in the above table, it could be seen that men are more supportive to recitation commercial performances than women, especially men with master degrees and above or with college degrees. Also, men are more willing to buy tickets for these performances.

Table 5 The relationship between the respondent's gender / educational degree and his/her interest in the relevant creative products

\begin{tabular}{|c|c|c|c|c|}
\hline X\Y & A. Interested & B. Just so-so & C. Not interested & Subtotal \\
\hline A. Male /A. Master and above & $12(52.17 \%)$ & $8(34.78 \%)$ & $3(13.04 \%)$ & 23 \\
\hline A. Male /B. Bachelor & $14(43.75 \%)$ & $13(40.63 \%)$ & $5(15.63 \%)$ & 32 \\
\hline A. Male /C. College & $7(46.67 \%)$ & $4(26.67 \%)$ & $4(26.67 \%)$ & 15 \\
\hline A. Male /D. Below college & $6(54.55 \%)$ & $2(18.18 \%)$ & $3(27.27 \%)$ & 11 \\
\hline B. Female /A. Master and above & $10(37.04 \%)$ & $13(48.15 \%)$ & $4(14.81 \%)$ & 27 \\
\hline B. Female /B. Bachelor & $30(44.78 \%)$ & $30(44.78 \%)$ & $7(10.45 \%)$ & 67 \\
\hline B. Female /C. College & $19(50 \%)$ & $15(39.47 \%)$ & $4(10.53 \%)$ & 38 \\
\hline B. Female /D. Below college & $7(63.64 \%)$ & $1(9.09 \%)$ & $3(27.27 \%)$ & 11 \\
\hline
\end{tabular}

The main purpose of the survey in Table 5 is to collect information about the potential customer groups of creative products related to recitation shows. It could be seen from the percentages that males with master degrees and above or with college degrees and below are more interested in the creative products than males of college degrees or bachelor's degrees; the latter are more interested in the recitation art itself. As for females, those who have college degrees and below are more 
interested in the creative products, and those with higher educational degrees only show a mediocre interest in recitation performances.

From them, we could learn that, in Xiamen Island, people with higher educational degrees are generally not so interested in recitation performances, and that among this group of people, males are more interested in recitation performances than females. These findings are the same with the conclusions made by vice president Jia Zhaohui during the previous interview, that is, the social groups who are interested in recitation and willing to participate in the relevant activities in Xiamen Island are mainly people with bachelor's degrees or college degrees.

The second group of cross-over analyses mainly analyzes the relationship between the respondent's income level and the development status of Xiamen's recitation cause.

Table 6 The relationship between the respondent's income level and his/her interest in recitation

\begin{tabular}{|c|c|c|c|c|}
\hline $\mathrm{X} \backslash \mathrm{Y}$ & A. Interested & B. Just so-so & C. Not interested & Subtotal \\
\hline A. 10000 yuan and above & $25(64.1 \%)$ & $11(28.21 \%)$ & $3(7.69 \%)$ & 39 \\
\hline B. 6000 - 9999 yuan & $42(66.67 \%)$ & $16(25.4 \%)$ & $5(7.94 \%)$ & 63 \\
\hline C. 3000 - 5999 yuan & $41(60.29 \%)$ & $16(23.53 \%)$ & $11(16.18 \%)$ & 68 \\
\hline D. Below 2999 yuan & $16(29.63 \%)$ & $29(53.7 \%)$ & $9(16.67 \%)$ & 54 \\
\hline
\end{tabular}

The above table demonstrates how Xiamen Island residents of different income levels are interested in recitation. We could see from the percentages that over $60 \%$ respondents of a monthly income of 3000 yuan or more are interested in recitation. And the number of respondents shows that respondents who earn 3000 to 9999 yuan per month account for the biggest percentage of those who are interested in recitation. This largely fits the survey results about Xiamen Recitation Society that the investigator has obtained from the previous interview. Nonetheless, different from the interview results, the questionnaires show that the groups interested in recitation are mainly people of average income rather than people of below-average income.

Table 7 The relationship between the respondent's income level and his/her willingness to watch the independent recitation performances

\begin{tabular}{|c|c|c|c|}
\hline $\mathrm{X} \backslash \mathrm{Y}$ & A. Yes & B. No & Subtotal \\
\hline A. 10000 yuan and above & $29(74.36 \%)$ & $10(25.64 \%)$ & 39 \\
\hline B. 6000 - 9999 yuan & $50(79.37 \%)$ & $13(20.63 \%)$ & 63 \\
\hline C. 3000 - 5999 yuan & $48(70.59 \%)$ & $20(29.41 \%)$ & 68 \\
\hline D. Below 2999 yuan & $30(55.56 \%)$ & $24(44.44 \%)$ & 54 \\
\hline
\end{tabular}

According to the above table, all income groups in Xiamen have the desire to watch independent recitation performances. Among them, nearly $80 \%$ respondents who have a monthly income from 6000 to 9999 yuan are willing to watch independent recitation performances, and over $70 \%$ respondents who have a monthly income of 3000 yuan or more will make the same choice.

Table 8 The relationship between the respondent's income level and whether the respondent will buy ticket to watch recitation commercial performances

\begin{tabular}{|c|c|c|c|}
\hline $\mathrm{X} \backslash \mathrm{Y}$ & A. Yes & B. No & Subtotal \\
\hline A. 10000 yuan and above & $23(58.97 \%)$ & $16(41.03 \%)$ & 39 \\
\hline B. $6000-9999$ yuan & $40(63.49 \%)$ & $23(36.51 \%)$ & 63 \\
\hline C. 3000 - 5999 yuan & $31(45.59 \%)$ & $37(54.41 \%)$ & 68 \\
\hline D. Below 2999 yuan & $13(24.07 \%)$ & $41(75.93 \%)$ & 54 \\
\hline
\end{tabular}

Table 7 mainly shows the respondent's interest in independent recitation performances, while Table 8 tells about the willingness of respondents of different income levels to buy tickets to recitation commercial performances. As the superstructure is determined by the economic base, about $60 \%$ respondents with a monthly income of 6000 yuan or more are willing to buy tickets to 
watch recitation commercial performances, while more than half of respondents with a monthly income of 5000 yuan or less haven't shown such willingness.

\section{Conclusions and Prospect}

Combining the development potential of the recitation art itself in Xiamen Island, and coupled with the results of questionnaire survey, we believe that several measures could be taken to stimulate the development of recitation activities in Xiamen. Firstly, we are supposed to attract more male reciters. As have been shown in the interview and questionnaire survey results, the participants of Xiamen's recitation activities and those attending the questionnaire survey are mainly females. Besides, in this survey, there were one male interviewee and four female interviewees. Thus, we could attract more male participants in the future development. Secondly, we are supposed to hold more recitation activities of high quality and high input so as to attract more people of higher educational background or of high income. During the interview, it's found that most recitation participants are with college degrees or bachelor's degrees and the majority of them belong to the middle or lower middle-income groups. As the questionnaire survey has shown, recitation enjoys as much attention among most people of higher educational background or of high income as among the other social groups. The statistical differences in the data gained from the interview and the questionnaire survey demonstrate directly that the potential and passion of the groups of higher educational background or of high income haven been insufficiently inspired, especially with the development status of recitation activities in Xiamen Island taken into consideration. Therefore, in the future development, the characteristics of these two special groups of people should be taken into consideration in the creation of recitation activities so as to further promote the Xiamen's recitation development.

When it comes to the recitation performance training and its commercialized development, Xiamen Island's recitation training market is now facing the problem of disorderly development in which the good and the bad are mixed together. Hence, before there will be relevant laws and industry regulations, it's necessary for the culture and propaganda departments to take the initiative, and essential for the Song and Dance Theater, the relevant associations and the non-profit institutions concerned (for instance, the Children's Palace) to open some non-profit recitation training courses. These cost-effective courses will serve as an indirect force to purify the market and will help to compress the survival space of those pseudo-artists and pseudo-practitioners. After the market gets purified through its own eliminations, the commercial training institutions of high quality as well as their commercial value will gain further development, and true artists will be able to achieve the maximization of their own artistic talent. From the training cycles of other training projects, it could be seen that the above elimination process will take at least one to two years. In the aspect of performance, live television broadcast still remains the dominant way for the majority of recitation audiences to watch recitation performances, so their interest in recitation programs could not be turned into a driving force for the relevant market expansion. Also, there are still some consumers in Xiamen who maintain their habitual thinking mode of not watching recreational and sports performances unless with free tickets. Besides, people of medium income just have a mediocre interest in watching the recitation commercial performances. Due to these common factors, the market in Xiamen Island is and will remain unqualified for large and independent commercial shows of recitation programs in a short period of time. Though common recitation commercial shows are relatively common in Xiamen Island, the negative events resulting from inadequate supervision also form a harmful factor in the upward commercialized development of Xiamen's recitation. In a nutshell, it will still take some time for Xiamen to hold large-scale recitation commercial performances, and common recitation commercial performances call for urgent regulations. From appearing in the market, to being eliminated by the market, or to developing under the market regulation, any industry will experience such a market development cycle, and different industries will take different amount of time to complete this process. Therefore it's impossible to make objective predictions on the prospects of the commercialized development of Xiamen's recitation activities. The successful release of “Ode to Chen Jiageng” has accumulated 
a lot of important experience for the future recitation programs to develop into independent shows. All the other cultural icons (such as Gulangyu Islet, Zheng Chenggong, etc.) in Xiamen could draw successful experience from the show of "Ode to Chen Jiageng" and thus be fashioned into independent recitation performances. And to these creations, their core should still be a complete

and souled main line of narration, detailed examples, exquisite making and high input. Carrying forward this principle of creation, it's possible for Xiamen Island or the entire Xiamen City to create new hallmark and independent recitation performances within the following three years.

\section{References}

[1]. Bullot N J, Reber R. The artful mind meets art history: Toward a psycho-historical framework for the science of art appreciation [J]. Behavioral and Brain Sciences, 2013, 36 (02): 123-137.

[2]. Jakesch M, Leder H. Finding meaning in art: Preferred levels of ambiguity in art appreciation[J]. The Quarterly Journal of Experimental Psychology, 2009, 62 (11): 2105-2112.

[3]. Rump E E, Southgate V. Variables affecting aesthetic appreciation, in relation to age[J]. British Journal of Educational Psychology, 1967, 37 (1): 58-72.

[4]. Li Yalin. The several critical questions in the art of recitation [J]. Journal of Xinxiang Teachers College 2006 (3). (in Chinese)

[5]. Wang Qiongzi. On the cultivation of the recitation art of college students [J]. South Forum 2008 (11). (in Chinese) 